\title{
Effects of Rosemary and husk on hemogram and some biochemical parameters during treatment of ulcerative colitis in rats
}

\author{
Magdy, S. Amer ${ }^{1}$, Rasha, M. Saleh ${ }^{2}$ and Mayada ${ }^{1}$, A. Rashad \\ ${ }^{1}$ Department of Pharmacology, Faculty of Veterinary Medicine, Mansoura University, Mansoura, Egypt \\ ${ }^{2}$ Department of Physiology, Faculty of Veterinary Medicine, Mansoura University, Mansoura, Egypt
}

\begin{abstract}
Objective: The effects of rosemary $(10 \mathrm{mg} / \mathrm{kg} \mathrm{B.W})$ and husk $(5 \mathrm{mg} / \mathrm{kg} \mathrm{B.W})$ on hemogram, GSH , CAT , NO, IL-1 $\beta$ and IL-10 of rats (40 albino rats) were investigated Design:Experimental study

Animals: 40 albino rats

Procedures: The 1st group was served as negative control, while the remaening groups ( $2 \mathrm{nd}, 3 \mathrm{rd}$ and $4 \mathrm{th}$ ) were given acetic acid (4\%) to induce ulcerative colitis (UC). Then the 2nd group was used as positive control, the 3rd group was orally given rosemary daily for 7 days, while the 4 th group was orally administerated husk daily for 7 days. Blood and serum samples were collected from all groups at one week post dosing

Results: The obtained results revealed that, both the tested plants induced a significant increase in RBCs, Hb, PCV\% and lymphocyte counts and a significant decrease in WBC, neutrophil, monocyte and blood platelets of treated rats compared with the positive control group.
\end{abstract}

Conclusion and clinical relevance: In addition rosemary and husk evoked a significant increase in GSH, CAT and IL-10 and a significant decrease in NO and IL-1 $\beta$ in serum of treated rats in comparions with the positive control group.

Keywords: Rosmary, husk, rats, ulcerative colitis

\section{INTRODUCTION}

Ulcerative colitis (UC) is an idiopathic inflammatory bowel disease disturbs the colonic mucosa and characterized clinically by diarrhea, abdominal pain in addition to hematochezia. The incidence of ulcerative colitis is getting to be common in the world because of alterations in dietary habits (Kakodkar and Mutlu, 2017).

Many of the serious complications of UC may be developed including toxic megacolon which characterized by a sepsis-like syndrome and extensive distension of the colon, massive bleeding (caused microcytic anemia) in addition to peptic ulcers, osteoporosis, colorectal cancer due to chronic inflammation and autoimmune hepatitis diseases (Saubermann et al., 2017).

The etiology of ulcerative colitis is yet not completely recognized however it is broadly known that multifactor involving genetic, environmental, microbial and immune factors interplay important roles in UC occurrence (Santos et al., 2018).

Antispasmodics can be used in ulcerative colitis to relieve some of the symptoms such as spasm, bloating and abdominal pain. They reduce the motility of the intestine by the prevention of contractile gut wall pathways as well as improve bowel behaviors through increasing colonic transit time, consequently decreasing stool passage frequency (Kim et al., 2018).

Medicinal herbs are used as an alternative source to synthetic compounds against colitis with less or no adverse effects. They cause correction of the bowel immune response, amelioration of the antioxidant status, alteration in polyunsaturated fatty acids uptake, improvement of intestinal mucosal barrier restoration, controlling of the intestinal microflora, intestinal motility, bile-pancreatic excretions, in addition to nutritional particles retention (Olamilosoye et al. 2018).

Among these natural immunomodulatory medicinal herbs are the Rosemary (Rosmarinus officinalis L.) which belongs to the family Lamiaceae. Rosmarinus officinalis L. has antinociceptive activities in addition to the ability to block nuclear factor kappa B which hyperactivated in ulcerative colitis. This blocking will decline the expression of nitric oxide synthase, leukocyte activity and pro-inflammatory enzymes action such as interleukin 1 beta (Jin et al., 2017; De Oliveira al., 2019).

Psyllium husk (Plantago ovata forsk) is a multipurpose annual immunomodulatory medicinal herb belonging to the 
family Plantaginaceae. The Psyllium husk seed mucilaginous product creating a gel-dietary fiber consists of soluble and insoluble polysaccharides (cellulose, hemicellulose, and lignin) which enable lubrication and assist propulsion of colon contents by serving as hydrophilic colloids that display good water-holding and swelling effects improved UC symptoms such as diarrhea, constipation, incomplete evacuation, and bloating (Bagheri et al., 2018).

This study aimed to evaluate the effects of aqueous extract of rosemary and Plantago ovata husk powder on rats through: measurement of some hematological parameters (RBCs, WBCs count, $\mathrm{Hb}$ concentration, PCV\%, and blood platelets) and evaluation of serum biochemical parameters (reduced glutathione (GSH), and catalase (CAT), serum nitric oxide (NO) and some cytokines (IL-1 $\beta$ and IL-10)

\section{MATERIALS AND METHODS}

\subsection{Material}

The Medicinal plants:

A. Rosmarinus officinalis L. (Rosemary):

Rosmarinus officinalis L. was obtained from chemistry department, Research Center of Agriculture, Cairo, Egypt.

Dose: $10 \mathrm{mg} / \mathrm{kg}$ B.W of rats /day according to Haloui et al., (2000).

B. Psyllium seed Husk powder (Plantago ovate husks):

Psyllium seed Husk powder available as Mincera sachet each $100 \mathrm{gm}$ contains 79gm psyllium husk was purchased from Family Pharmacia, Pharmaceutical Company. Egypt.

Dose: $5 \mathrm{gm} / \mathrm{kg} \mathrm{B.W}$ of rats /day which modified according to a therapeutic dose of human (Paget and Barnes, 1964).

Experimental Animals

A total of forty healthy albino rats aged one month, and nearly $150-200 \pm 1.58 \mathrm{~g}$ each. They were obtained from the scientific research center in Mansoura University (MERK). Rats were housed in Department of Pharmacology, Faculty of Veterinary Medicine, Mansoura University. They were acclimatized for 2 weeks and kept in cages under a 12 hours light/dark cycle at $22 \pm 2 c^{\circ}$ and $60 \%$ humidity. Rats had free access to water and balanced rodent pelleted chow.

\section{2-Methods}

Preparation of medicinal plants extract:

A. Aqueous extract of Rosmarinus officinalis L. (Rosemary) was prepared according to Haloui et al., (2000)

B. Psyllium seed Husk was powder according to (Paget and Barnes, 1964).

Animal grouping:

The experiment was conducted on 40 albino rats (4 weeks old). After two weeks period of acclimatization in plastic cages condition. Rats were classified into 4 similar groups (each of 10 rats) as follow: a- $1^{\text {st }}$ Group (Control): the normal negative control group given normal saline orally and phosphate buffer saline injected I/R once a week.

b- $2^{\text {nd }}$ Group (Acetic acid): acetic acid -ulcerated positive control group.

c- $3^{\text {rd }}$ Group (Rosemary therapeutic): acetic acid-ulcerative colitis treated with aqueous extract of Rosmarinus officinalis L. (10 mg/kg B.W) orally daily for one week.

d- $4^{\text {th }}$ Group (Husk powder therapeutic): acetic acid ulcerative colitis treated with Psyllium seed Husk powder (5 mg/kg B.W) orally daily for one week.

Blood and tissue sampling:

Blood and serum samples were collected from all groups at one week post dosing. Five rats were picked up randomly from each group and were anesthetized with ether then while the heart was still beating two blood samples were collected from heart puncture individually. The first blood samples were collected in heparinized test tube for hematological examination while the second blood samples were collected into a dry sterile centrifuge tube and allowed to clot at room temperature for 45 minutes, and then centrifuged for 10 minutes at $3000 \mathrm{rpm}$ to obtain sera that were separated and used for biochemical examination. Hematological Examination

RBCs, WBCs count, $\mathrm{Hb}$ concentration, PCV, and platelets were determined according to method of Coles, (1986).

Evaluation of serum oxidative stress and antioxidant enzymes: a- Determination of hepatic glutathione reduced (GSH) according to Beutler et al., (1963).

b- Determination of hepatic catalase (CAT) according to Aebi, (1984).

Immunological studies

a- Determination of nitric oxide (NO) according to Montgomery and Dymock, (1961).

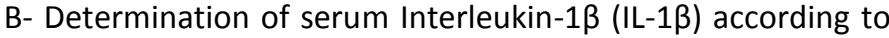
Martinon and Tschopp, (2007).

C-Determination of serum Interleukin-10 (IL-10) according to Lobell, (1998).

Statistical Analysis

All data were statistically evaluated by used statistical software program (SPSS for Windows, version 23, USA). The mean \pm standard error for five rats in each group was estimated for each variable using a one-way analysis of variance (ANOVA) (SAS, 2001).

\section{RESULTS}

\section{Effects of rosemary and husk on hemogram of treated rats}

As shown in Tables (1-2), the recorded results regarding the effect of the tested aqueous extract of Rosmarinus officinalis $L$. leaves in rats showed significant increase in RBCs, $\mathrm{Hb}, \mathrm{PCV} \%$ and lymphocyte counts and significant decrease in blood platelets, WBC, neutrophil, monocyte with insignificant 
changed in eosinophil and basophil counts when compared with positive control (acetic acid ulcerative rats) group.
Table (2): Effects rosemary, and husk on leukogram of Ulcerative colitis rats. $n=5 \quad$ (Mean \pm S.E)

Table (1): Effects of rosemary and husk on erythrogram of Ulcerative colitis rats. $\quad n=5$

(Mean \pm S.E)

\begin{tabular}{|c|c|c|c|c|c|c|c|}
\hline & Groups & $\begin{array}{r}\mathrm{RBCs} \\
106 / \mu \mathrm{L} \\
106 / \mu \mathrm{L}\end{array}$ & $\begin{array}{l}\mathrm{Hb} \\
\mathrm{g} / \mathrm{dl} \\
\mathrm{g} / \mathrm{dl}\end{array}$ & $\begin{array}{l}\text { PCV } \\
\quad \%\end{array}$ & $\begin{array}{l}\text { MCV } \\
\text { fl }\end{array}$ & $\begin{array}{c}\mathrm{MCH} \\
\mathrm{pg}\end{array}$ & $\begin{array}{l}\mathrm{MCHC} \\
\%\end{array}$ \\
\hline G1 & $\begin{array}{l}\text { Negative } \\
\text { control }\end{array}$ & $\begin{array}{l}8.65 \pm 0 . \\
58^{\mathrm{a}}\end{array}$ & $\begin{array}{l}13.48 \pm \\
0.88^{\mathrm{a}}\end{array}$ & $\begin{array}{l}41.83 \\
\pm 1.60 \\
b\end{array}$ & $\begin{array}{l}48.35 \\
\pm 0.55 \\
\text { ab }\end{array}$ & $\begin{array}{l}15.58 \pm \\
0.57^{\mathrm{a}}\end{array}$ & $32.23 \pm 0.55^{\mathrm{a}}$ \\
\hline G2 & $\begin{array}{l}\text { Posative } \\
\text { control }\end{array}$ & $\begin{array}{l}6.10 \pm 0 . \\
53^{b}\end{array}$ & $\begin{array}{l}9.55 \pm 0 \\
.46^{\mathrm{b}}\end{array}$ & $\begin{array}{l}30.1 \pm \\
0.92^{c}\end{array}$ & $\begin{array}{l}49.34 \\
\pm 1.82 \\
\text { a }\end{array}$ & $\begin{array}{l}15.66 \pm \\
1.03^{\mathrm{a}}\end{array}$ & $31.73 \pm 1.82^{\mathrm{a}}$ \\
\hline G3 & $\begin{array}{l}\text { Rosemary } \\
\text { therapeutic }\end{array}$ & $\begin{array}{l}9.22 \pm 0 . \\
77^{\mathrm{a}}\end{array}$ & $\begin{array}{l}13.89 \pm \\
0.52^{\mathrm{a}}\end{array}$ & $\begin{array}{l}43.87 \\
\pm 0.84 \\
a\end{array}$ & $\begin{array}{l}47.48 \\
\pm 2.13 \\
\text { bc }\end{array}$ & $\begin{array}{l}15.06 \pm \\
1.15^{\mathrm{a}}\end{array}$ & $31.72 \pm 2.13^{\mathrm{a}}$ \\
\hline G4 & $\begin{array}{l}\text { Husk } \\
\text { powder } \\
\text { therapeuti }\end{array}$ & $\begin{array}{l}8.19 \pm \\
0.73^{a}\end{array}$ & $\begin{array}{l}13.02 \\
\pm 0.62^{a}\end{array}$ & $\begin{array}{l}40.5 \\
4 \pm 0 \\
89^{b}\end{array}$ & $\begin{array}{l}49.5 \\
0 \pm 1 \\
94^{a}\end{array}$ & $\begin{array}{l}15.90 \\
\pm 1.13^{\mathrm{a}}\end{array}$ & $32.12 \pm 1.94^{a}$ \\
\hline
\end{tabular}

Different letters in the same column means significant difference at $(P \leq .05)$

II - Effects of rosemary and husk on some biochemical parameters in serum of treated rats:

As in Table (3), the results regarding the effect of tested aqueous extract of Rosmarinus officinalis $L$. leaves revealed a significant increase in GSH , CAT , and IL-10 levels with a significant decrease in NO and IL-1 $\beta$ when compared with positive control (acetic acid ulcerative rats) group.

Table (3): Effects of rosemary, and husk on some biochemical parameters of Ulcerative colitis rats. $n=5$ (Mean \pm S.E)

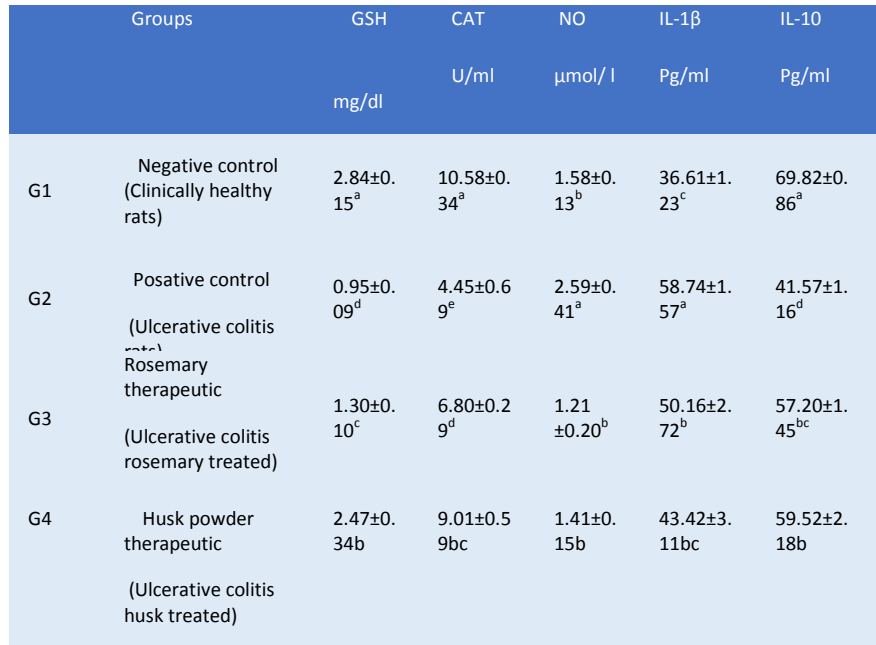

Different letters in the same column means significant difference at $(\mathrm{P} \leq .05)$

\section{DISCUSSION}

These findings are in accordance with Yamamoto et al. (2005) found that the use of rosemary showed significant antithrombotic activity. Also, Sancheti and Goyal (2007) who found that pre-treated mice with aqueous extract of Rosmarinus officinalis L. leave orally for 5 consecutive days induced significantly elevated in the values of RBC and PCV \% . In the same line Anadon et al., (2008) said that eosinophils and basophils assessed 2 weeks after administration of rosemary extracts (single oral dose at $2,000 \mathrm{mg} / \mathrm{kg}$ of body weight) to rats, the authors recorded a non-significant different compared with those of control. Moreover, Benincá et al., (2011) and Rekik et al., (2012) reported that Rosmarinus officinalis L. Extracts reduced the leukocyte activation during inflammation. Furthermore, Abd El-Latif et al. (2013) found that the PCV, $\mathrm{Hb}$ concentration and lymphocytic percent were significantly increased. Meanwhile, monocytes percent was significant decrease with no significant differences in heterophil and eosinophil in one day-old commercial Ross broiler chicks that supplemented with rosemary oil at a dose (100 and $200 \mathrm{mg} / \mathrm{kg} /$ daily for 21 days).

As in Tables (1-2), the results obtained regarding the effect of Husk seeds powder in rats showed significant increase in RBCs, $\mathrm{Hb}, \mathrm{PCV} \%$ and lymphocyte counts and significant decrease in platelets,WBC, neutrophil, monocyte with insignificant changed in eosinophil and basophil counts when compared with positive control (acetic acid ulcerative rats) group. These findings are in agreement with Mohammadi et al., (2014) who mentioned that alcoholic extract of plantago ovata significantly improved hematological parameters in related to RBCs count PCV and hence addition of this extract to daily diet could enhance hematopoiesis. 
As in Table (3), the results regarding the effect of tested aqueous extract of Rosmarinus officinalis L. leaves revealed a significant increase in GSH , CAT, and IL-10 levels with a significant decrease in NO and IL-1 $\beta$ when compared with positive control (acetic acid ulcerative rats) group. These findings are in agreement with Sancheti and Goyal, (2007) who found that orally administration of rosemary extract once daily at dose $1000 \mathrm{mg} / \mathrm{kg}$ B.W for five consecutive days in rats showed a significant elevation in the values of hepatic and blood GSH. Moreover, Khalil et al., (2012) recorded a significant increase in serum GSH level and CAT in hyperglycemic rats after administration of $200 \mathrm{mg} / \mathrm{kg}$ body weight aqueous extract of Rosmarinus officinalis L. for 21 days. Similarly, This result is in accordance with Cheung and Tai, (2007) and Rekik et al., (2012) who discovered the crude rosemary extract that has antioxidant and anti-inflammatory activities through inhibition of NO production and reduction of IL-1 $\beta$ level. Furthermore, ELnaggar et al. (2016) and Ghozlan et al., (2017) mentioned that Rosmarinus officinalis L. dietary administration in broiler fed basal diet significantly increased the IL-10 levels due to antioxidant phenolic compounds.

As in Table (3), the recorded results regarding the effect of Husk seeds powder showed a significant increase in GSH , CAT , and IL-10 levels with a significant decrease in IL-1 $\beta$ and NO when compared with positive control (acetic acid ulcerative rats) group. It is important to note that the effect of Plantago psyllium seeds may be due to their antioxidant potential which represented by their rich content of flavonoids, alkaloids, polyunsaturated fatty acids, sulfur containing amino acids, and metabolites. Furthermore, high levels of caffeic acid that possess non-enzymatic antioxidant activity such as scavenging free radicals, and enzymatic antioxidant activity such as increasing protein level of antioxidant enzymes (Kalaiarasi and Pugalendi, 2011). In accordance with the present findings, El-Feky et al., (2018) revealed that GSH level significantly ameliorated in the tissues of ketoprofen-induced hepatorenal toxicity rats after orally treatment with aqueous Plantago ovata extract. Also, This result is accepted with Rodríguez-Cabezas et al., (2002) who indicated that NO level significantly reduced in the inflamed rat colon dietary supplemented with $5 \%$ Plantago ovata seeds for 2 weeks before trinitrobenzenesulfonic acid colitis induction. In the same manner, Rodríguez-Cabezas et al., (2003) who found the dietary supplemented with $5 \%$ Plantago ovata seeds for 13 weeks before evaluation of the colonic infammatory status significantly reduced that NO level in transgenic rats. Moreover, Ogata et al., (2017) revealed that Psyllium induced immunomodulatory effect by (significantly decrease the elevated IL-1 $\beta$ in experimentally dextran sodium sulphate ulcerative colitis mice).

Conflict of interest

Authors declare that they have no conflict of interest

\section{REFERENCES}

Abd El-Latif, S. A., Saleh, N. S., Allam, T. S., and Ghazy, E. W. (2013): The effects of rosemary (Rosemarinus afficinalis) and garlic (Allium sativum) essential oils on performance, hematological, biochemical and immunological parameters of broiler chickens. British Journal of Poultry Science, 2: 16-24.

Aebi, H. (1984): Methods in Enzymatic Analysis. Academic Press, New York; 3: PP 276-286.

Anadon, A., Martinez-Larranaga, M. R., Martinez, M. A., Ares, I., Garcia-Risco, M. R., Senorans, F. J., and Reglero, G. (2008): Acute oral safety study of rosemary extracts in rats. Journal of food Protection, 71(4): 790-795

Bagheri, S. M., Zare-Mohazabieh, F., Momeni-Asl, H., Yadegari, M., Mirjalili, A., and Anvari, M. (2018): Antiulcer and hepatoprotective effects of aqueous extract of Plantago ovata seed on indomethacin-ulcerated rats. Biomedical Journal, 41(1): 41-45.

Benincá, J. P., Dalmarco, J. B., Pizzolatti, M. G., and Fröde, T. S. (2011): Analysis of the anti-inflammatory properties of Rosmarinus officinalis L. in mice. Food Chemistry, 124(2): 468-475.

Beutler, E, Duron, O. and Kelly, B.M. (1963): Improved method for the determination of blood glutathione. Journal of Laboratory Clinical Medicine; 61: 882-888.

Cheung, S., and Tai, J. (2007): Anti-proliferative and antioxidant properties of rosemary Rosmarinus officinalis. Oncology Reports, 17(6): 1525-1531.

Coles, E.H. (1986): Veterinary Clinical Pathology. 4th Edition, W.B. Saunders Company, Philadelphia: 17-19

De Oliveira, J. R., Camargo, S. E. A., and de Oliveira, L. D. (2019): Rosmarinus officinalis L.(rosemary) as therapeutic and prophylactic agent. Journal of Biomedical Science, 26(1):5.

El-Feky, A. M., Elbatanony, M. M., Naser, A. F. A., and Hamed, M. A. (2018): A therapeutic insight of carbohydrate and fixed oil from Plantago ovata L. seeds against ketoprofen-induced hepatorenal toxicity in rats. Bulletin of the National Research Centre, 42(1): 28.

ELnaggar, A. S., Abdel-Latif, M. A., El-Kelawy, M. I., and Abd, E. H. (2016): Productive, physiological and immunological effects of rosemary leaves meal (Rosemarinus officinalis) supplementing to broiler diet. Egyptian Poultry Science Journal, 36(III): 859-873.

Ghozlan, S. A., El-Far, A. H., Sadek, K. M., Abourawash, A. A., and Abdel-Latif, M. A. (2017): Effect of rosemary (Rosmarinus officinalis) dietary supplementation in broiler chickens concerning immunity, antioxidant status, and performance. Alexandria Journal of Veterinary Sciences, 55(1): 152-161

Haloui, M., Louedec, L., Michel, J. B., and Lyoussi, B. (2000): Experimental diuretic effects of Rosmarinus officinalis and Centaurium erythraea. Journal of Ethnopharmacology, 71(3): 465-472.

Jin, B. R., Chung, K. S., Cheon, S. Y., Lee, M., Hwang, S., Hwang, S. N., and An, H. J. (2017): Rosmarinic acid suppresses colonic inflammation in dextran sulphate sodium (DSS)-induced mice via dual inhibition of NF-kB and STAT3 activation. Scientific reports, 7: 46252.

Kakodkar, S., and Mutlu, E. A. (2017): Diet as a therapeutic option for adult inflammatory bowel disease. Gastroenterology Clinics, 46(4): 745-767.

Kalaiarasi p., and Pugalendi K.V. (2011): Protective effect of 18b-glycyrrhetinic acid on lipid peroxidation and antioxidant enzymes in experimental diabetes. J.Ph. Res.; 4 (1): 107- 111.

Khalil, O. A., Ramadan, K. S., Danial, E. N., Alnahdi, H. S., and Ayaz, N. O. (2012): Antidiabetic activity of Rosmarinus officinalis and its relationship with the antioxidant property. African Journal of Pharmacy and Pharmacology, 6(14): 1031-1036.

Kim, D., Kim, W., Jeong, S., Kim, D., Yoo, J. W., and Jung, Y. (2018): Therapeutic switching of sulpiride, an anti-psychotic and prokinetic drug, to an anticolitic drug using colon-specific drug delivery. Drug Delivery and Translational Research, 9(1): 334-343

Lobell, A. (1998): Methodology for determination of IL-10. Journal of Experimental Medicine, 187(9):1543-1548. 
Martinon, F., and Tschopp, J. (2007): Inflammatory caspases and inflammasomes: master switches of inflammation. Cell Death and Differentiation, 14(1): 10.

Mohammadi, M. J., Alishahi, M., Aramon, A., and Jahantigh, R. (2014): Studies on alcoholic extract of plantago ovata on some hematological parameters of Oncorhynchus mykiss. Breeding and Aquaculture Sciences Quarterly Spring, 2 (2); 59 - 70.

Montgomery, H.A. and Dymock, J.F. (1961): Determination of Nitric Oxide. Analyst; 86:414.

Ogata, M., Ogita, T., Tari, H., Arakawa, T., and Suzuki, T. (2017) : Supplemental psyllium fibre regulates the intestinal barrier and inflammation in normal and colitic mice. British Journal of Nutrition, 118(9), 661-672.

Olamilosoye, K. P., Akomolafe, R. O., Akinsomisoye, O. S., Adefisayo, M. A., and Alabi, Q. K. (2018): The aqueous extract of Ocimum gratissimum leaves ameliorates acetic acid-induced colitis via improving antioxidant status and hematological parameters in male Wistar rats. Egyptian Journal of Basic and Applied Sciences, 5(3): 220-227.

Paget and Barnes (1964): Evaluation of Drug Activities Paramacometrrics, Eds, Laurence and Bacharach, Vol.1, Academic Press,. NewYork. Radical Biology \& Medicine, 40:570- 580.

Rekik, I., Allassonniere, S., Carpenter, T.K. and Wardlaw, J.M. (2012): Medical image analysis methods in MR/CT-imaged acute- subacute ischemic stroke lesion: Segmentation, prediction and insights into dynamic evolution simulation models. A critical appraisal. Neuroimage Clin. 1: 16478.

Rodriguez-Cabezas, M. E., Galvez, J., Camuesco, D., Lorente, M. D., Concha, A., Martinez-Augustin, O., and Zarzuelo, A. (2003): Intestinal antiinflammatory activity of dietary fiber (Plantago ovata seeds) in HLA-B27 transgenic rats. Clinical Nutrition, 22(5): 463-471.

Rodríguez-Cabezas, M. E., Galvez, J., Lorente, M. D., Concha, A., Camuesco, D., Azzouz, S., and Zarzuelo, A. (2002): Dietary fiber down-regulates colonic tumor necrosis factor $\alpha$ and nitric oxide production in trinitrobenzenesulfonic acid-induced colitic rats. The Journal of Nutrition, 132(11): 3263-3271.

Sancheti, G., and Goyal, P. K. (2007): Prevention of radiation induced hematological alterations by medicinal plant Rosmarinus officinalis, in mice. African Journal of Traditional, Complementary and Alternative Medicines, 4(2): 165-172.

Santos, M. P. C., Gomes, C., and Torres, J. (2018): Familial and ethnic risk in inflammatory bowel disease. Annals of gastroenterology, 31(1): 14.

SAS (2001): Statistical Analysis System User's Guide: Statistics, Version 8.2. SAS Institute, NC, USA.

Saubermann, L. J., Deneau, M., Falcone, R. A., Murray, K. F., Ali, S., Kohli, R., and Jonas, M. M. (2017): Hepatic issues and complications associated with inflammatory bowel disease: a clinical report from the NASPGHAN inflammatory bowel disease and hepatology committees. Journal of pediatric gastroenterology and nutrition, 64(4): 639-652.

Yamamoto, J., Yamada, K., Naemura, A., Yamashita, T., and Arai, R. (2005): Testing various herbs for antithrombotic effect. Nutrition, 21(5): 580-587. 